\title{
Karmaşı Jeoloji ve Topografyaya Sahip Alanlarda Sentinel-2A Uydu Görüntülerinin Performansı Üzerine Bir Örnek Çalışma: Koyulhisar (Sivas-Türkiye)
}

\author{
Ayşe Betül Çalışkan ${ }^{1 *}$, Oktay Canbaz $^{2}$, Önder Gürsoy ${ }^{3}$ \\ 1* Hitit Üniversitesi, Teknik Bilimler Meslek Yüksekokulu, Mimarlık ve Şehir Planlama Bölümü, Çorum, Türkiye, (ORCID: 0000-0001-7724-6664), \\ aysebetulcaliskan@hitit.edu.tr \\ 2 Sivas Cumhuriyet Üniversitesi, Mühendislik Fakültesi, Jeoloji Mühendisliği Bölümü, Sivas, Türkiye (ORCID: 0000-0002-8161-1326), ocanbaz@cumhuriyet.edu.tr \\ ${ }^{3}$ Sivas Cumhuriyet Üniversitesi, Mühendislik Fakültesi, Harita Mühendisliği Bölümü, Sivas, Türkiye (ORCID: 0000-0002-1531-135X), ogursoy@cumhuriyet.edu.tr
}

(2nd International Conference on Applied Engineering and Natural Sciences ICAENS 2022, March 10-13, 2022)

(DOI: 10.31590/ejosat.1082487)

ATIF/REFERENCE: Çalışkan, A.B., Canbaz, O. \& Gürsoy, O. (2022). Karmaşık Jeoloji ve Topografyaya Sahip Alanlarda Sentinel2A Uydu Görüntülerinin Performansı Üzerine Bir Örnek Çalışma: Koyulhisar (Sivas-Türkiye). Avrupa Bilim ve Teknoloji Dergisi, (34), 387-395.

$\ddot{\mathbf{O z}}$

Bu çalışma, Sentinel 2A multispektral uydu görüntüsü kullanılarak jeolojik özelliklerin ortaya çıkarılmasına yönelik gerçekleştirilmiştir. Sivas ili Koyulhisar ilçesi sınırları içerisinde kalan çalışma alanında sedimanter ve volkanik kayaçlar yüzeylemektedir. Ayrıca, çalışma alanı, Türkiye'nin en önemli aktif fay zonlarından bir tanesi olan Kuzey Anadolu Fay Zonu (NAFZ) üzerinde konumlanmaktadır. Sarp ve engebeli topografyaya sahip olan bu alanda heyelan riski taşıyan birçok alan mevcuttur. Bu nedenle, çalışma alanının jeolojik özelliklerinin ortaya çıarılması oldukça önemlidir. Bu çalı̧̧mada, bant oranlama, minimum gürültü fraksiyonu (MNF) ve maksimum olabilirlik sınıflandırması (MLC) gibi uzaktan algılama teknikleri kullanılmıştır. Elde edilen sonuçlarda, mevcut jeolojik harita içerisinde formasyon ve birim sınırlarının gözden geçirilmesi ve yeniden çizilmesini gerektirecek sonuçlar elde edilmiştir.

Anahtar Kelimeler: Bant Oranlama, Minimum Gürültü Fraksiyonu, Maksimum Olabilirlik, Spektral Sınıflandırma

\section{A Case Study on the Performance of Sentinel-2A Satellite Images in Areas with Complex Geology and Topography: Koyulhisar (Sivas-Turkey)}

\begin{abstract}
This study was carried out to reveal geological characteristics using Sentinel-2A multispectral satellite image. Sedimentary and volcanic rocks crop out in the study area within the borders of the Koyulhisar town of Sivas province. In addition, the study area is located on the North Anatolian Fault Zone (NAFZ), one of the most important active fault zones in Turkey. There are many areas with landslide risk in this area, which has a steep and rugged topography. For this reason, it is very important to reveal the geological features of the study area. In the study, remote sensing techniques such as band ratio, minimum noise fraction (MNF) and maximum likelihood classification (MLC) were used. The results were obtained that would require the geological formations and unit boundaries to be reviewed and redrawn within the existing geological map.
\end{abstract}

Keywords: Band Ratio, Minimum Noise Fraction, Maximum Likelihood, Spectral Classification

\footnotetext{
*Sorumlu Yazar: aysebetulcaliskan@hitit.edu.tr
} 


\section{Giriş}

Uzaktan algılama teknolojileri, litolojik ve yapısal özellikler ile çizgisellik analizleri, mineral tespit ve dağılımının belirlenmesi, jeotermal sahaların araştırılması, volkanik aktivite araştırma ve gözlemleri gibi birçok jeolojik özelliğin araştırılması ve geliştirilmesinde büyük oranda katkı sağlamaktadırlar. Son yıllarda yapılan çalışmalarda, özellikle geniş alanlara sahip bölgelerde bu jeolojik özelliklerin hızlı ve verimli bir şekilde ortaya çıkarılmasında oldukça kullanılabilir veriler sunmaktadırlar. $\mathrm{Bu}$ çalışmalarda genellikle 0,4-2,5 $\mu \mathrm{m}$ bant aralığına sahip multispektral ve hiperspektral uydu görüntülerinden yararlanılmaktadır [1]. Landsat-5 TM, Landsat-7 ETM+, Landsat-8 OLI ve ASTER gibi multispektral uydu verileri hiperspektral uydu verilerine göre çoğunlukla düşük maliyetli ve kolay erişilebilir olmaları nedeniyle bu çalışmalarda yaygın bir şekilde kullanılmaktadır. Bütün bu uydu görüntüleri jeolojik özelliklerin ortaya çıkarılmasında oldukça verimli sonuçlar ortaya çıkarsada, diğer uydu görüntülerine göre daha yüksek çözünürlüklü kısa dalga boyu ve termal infrared bantları içeren ASTER uydu verileri, mineral ve litolojik haritalamalarda öncelikli tercih edilen veriler haline gelmişlerdir [2]. Yeryüzeyi, geçmişte olduğu gibi günümüzde de gerek doğa olayları ile (deprem, heyalan vb) gerekse insan eli yapılarıyla (bina, baraj, yol vb) sürekli değişim gösteren bir dinamik yapı haline gelmiştir. $\mathrm{Bu}$ değişimlerin uydu görüntüleri ile ortaya çıkarılması için güncel uydu verilerine ihtiyaç duyulmaktadır. Fakat mevcut uydulardan, Landsat-5' in 2013, Landsat-7'nin 2003 y1lında hasar görmesi nedeniyle kullanımdan kaldırılması ve ASTER SWIR dedektörünün ise yüksek sicaklık nedeniyle 2008 yılından günümüze kadar gelen süreçte SWIR görüntü vermemesi araştırıcıları yeni arayışlara yönlendirmiştir. Sentinel-2A multispektral uydu görüntüleri ise bunlardan bir tanesini oluşturmaktadır. Landsat ETM, SPOT ve daha az ölçüde ASTER uydu verilerine benzerliği ile günümüz çalışmalarında diğer uydu görüntülerinden kaynaklanan bu boşlukları doldurabilecek özelliğe sahiptirler [3]. Sentinel-2A verilerinin 90 nm'yi kapsayan bant geçişinde demir absorpsiyon özelliğine sahip olduğu [4], toprak bilimi ve jeoloji uygulamalarında ASTER VNIR-SWIR bantları ile simüle edilmiş Sentinel-2 verileri arasında iyi bir uyum olduğunu göstermiştir [3].

Ayrıca, jeolojik çalışmaların dışından Sentinel-2A uydu verileri, çok çeşitli uygulama alanlarını kapsamaktadır [5]. Bu çalışma alanları; yaprak alan indeksi [6], [7]; bitkilerdeki klorofil ve azot oranı [8]; su kalitesi belirleme [9]; göl kıyısındaki habitatların belirlenmesi [10]; bitki ve ağaç türlerinin sınıflandırılması [11]; su kalitesinin değerlendirilmesi [12] ve mercan resiflerinin haritalanması [13] şeklinde özetlenebilir [14].

Dünyada ve ülkemizde özellikle Sentinel-2A MSI uydu görüntü verileri ile yapılan, litolojik sınırların tespiti, yapısal özelliklerin ortaya çıkarılması ve ekonomik özelliğe sahip mineraller ile hidrotermal alterasyon minerallerinin tespitine yönelik çalışmalar çok fazla olmamakla birlikte verimli sonuçlar ortaya çıkarmıştır [2], [3], [14]-[20]

Çalışma alanı, Doğu Pontidlerin güney zonunda yeralmakta olup Sivas ili Koyulhisar ilçe sınırları içerisinde yer almaktadır. Ayrıca, Avrasya, Afrika ve Arabistan plakalarının etkileşimi ile Orta Miyosen'den günümüze kadar gelen neotektonik dönemin en önemli aktif fay zonlarından bir tanesi olan Kuzey Anadolu Fay Zonu üzerinde konumlanmaktadır. Yoğun tektonizma faaliyetleri ve topoğrafik eğimlerin etkisiyle bölgede geçmişten günümüze can ve mal kayıplarına neden olan birçok heyelan meydan gelmiştir. Son yıllarda, bölge heyelan riski taşıması nedeniyle birçok araştırmacının çalışma konusu olmuştur [21][26]. Bölgenin sarp ve engebeli bir topografyaya sahip olması ve jeolojik araştırmaları zorlaştırması nedeniyle uzaktan algılama yöntemlerini uygulamada tercih edilebilir özelliğe sahip bir alan olduğunu göstermektedir. İnceleme alanı içerisinde ve yakın çevresinde multispektral uydu görüntüleri ile yapılmış çalışmalar bulunmaktadır. Örneğin, [27], Sivas ili Gölova ilçesi ve çevresinde yaptıkları çalışmada ASTER uydu verisinde bir takım bant oranlama ve spectral sınıflandırma yöntemi ile litolojik haritalama yapmışlardır; [28], çalışma alanınıda içine multispektral uydu verisi ile litolojik haritalama ve Kuzey Anadolu Fay Zonu (KAFZ) üzerinde ki atım miktarını belirlemişlerdir. [29] ise çalışma alanının güneyinde multi- ve hiperspektral uydu verileri ile hidrotermal alterasyon haritalaması gerçekleştirmişlerdir. Ancak, bölgede ve yakın çevresinde $\mathrm{Bu}$ çalışmada, bölgede Sentinel-2a uydu görüntüsü ile yapılmış çalışma bulunmamaktadır. Sentinel-2A verilerinin, VNIR ve SWIR bölgelerinde Landsat verilerinden daha yüksek spektral ve uzaysal çözünürlükleri, ASTER verilerinden ise daha yüksek uzaksal çözünürlüğe sahip olması nedeniyle teorik olarak daha avantajlı olabileceği öngörülmektedir. Ayrıca, bölgenin dinamik özelliğe sahip olması nedeniyle, ücretsiz ve halen görüntü temin edilebildiği için çalışmada Sentinel-2A uydu verisi tercih edilmiştir.

Çalışmada, Sentinel 2A uydu görüntü verisinde bir seri bant oranlama, minimum gürültü fraksiyon ve maksimum olabilirlik yöntemi gibi görüntü zenginleştirme ve denetimli sınıflandırma yöntemleri uygulanarak litolojik sınırların tespiti ve uydu verisinin performansını belirlenmeye yönelik gerçekleştirilmiştir.

\section{Jeolojik Özellikler}

İnceleme alanı, güneyde İzmir-Ankara-Erzincan Sütur Zonu ile kuzeyde Doğu Pontidlerin arasında kalan bölgede yer almaktadır (Şekil 1a). Bölgesel ölçekte çalışma alanın temelini Palezoyik yaşlı metamorfik kayaçlar ile tektonik dokunakla bu birimleri üzerleyen Mesozoyik yaşlı ofiyolitik kayaçlar oluşturmaktadır. Bu birimler üzerinde uyumsuz olarak Alt-Orta Jura volkanik ve volkanosedimanterleri ile Üst Kretase yaşlı volkanikler gelmektedir. Paleosen-Eosen yaşlı granitoyitik kayaçlar bu birimleri ve Eosen volkanizmasının ürünlerini keserek bölgeye yerleşmiştir. Genç sedimanter birimler inceleme alanında bu birimleri uyumsuz olarak üzerlemektedir (Şekil 1b).

Tektonik olarak ise bölge KAFZ üzerinde kelkit vadisi içerisinde yer almaktadır. Tektonik aktivitelere bağlı olarak, fay zonlarında depremler, kabuk deformasyonları ve yerdeğiştirmeler milyonlarca yıldır süre gelmektedir. Dünya'da en iyi bilenen doğrultulu faylardan bir tanesi olan KAFZ üzerinde birçok araştırma yapılmış olup sağ yanal atımlı fay zonu olarak tanımlanmıştır [32]-[44]. Çalışma alanine da kapsayan bölgede yaklaşık atımın $85 \pm 5 \mathrm{~km}$ olduğu araştırıcılar tarafından belirlenmiştir [33], [41]. [36] tarafından KAFZ üzerinde Niksar (Tokat) ile Erzincan arasında yapılan GPS ölçümlerine dayanan çalışmada, batıdan doğuya doğru azalan atım miktarlarını $24.0 \pm$ $2.9^{\prime}$ dan $16.2 \pm 2.3 \mathrm{~mm} / \mathrm{y}$ ıl olarak belirlemişlerdir. Bu durum, bölgenin halen aktif bir tektonizma olduğunu, depremler ve heyelanlar açısından yüksek potansiyele sahip olduğunu göstermektedir. 


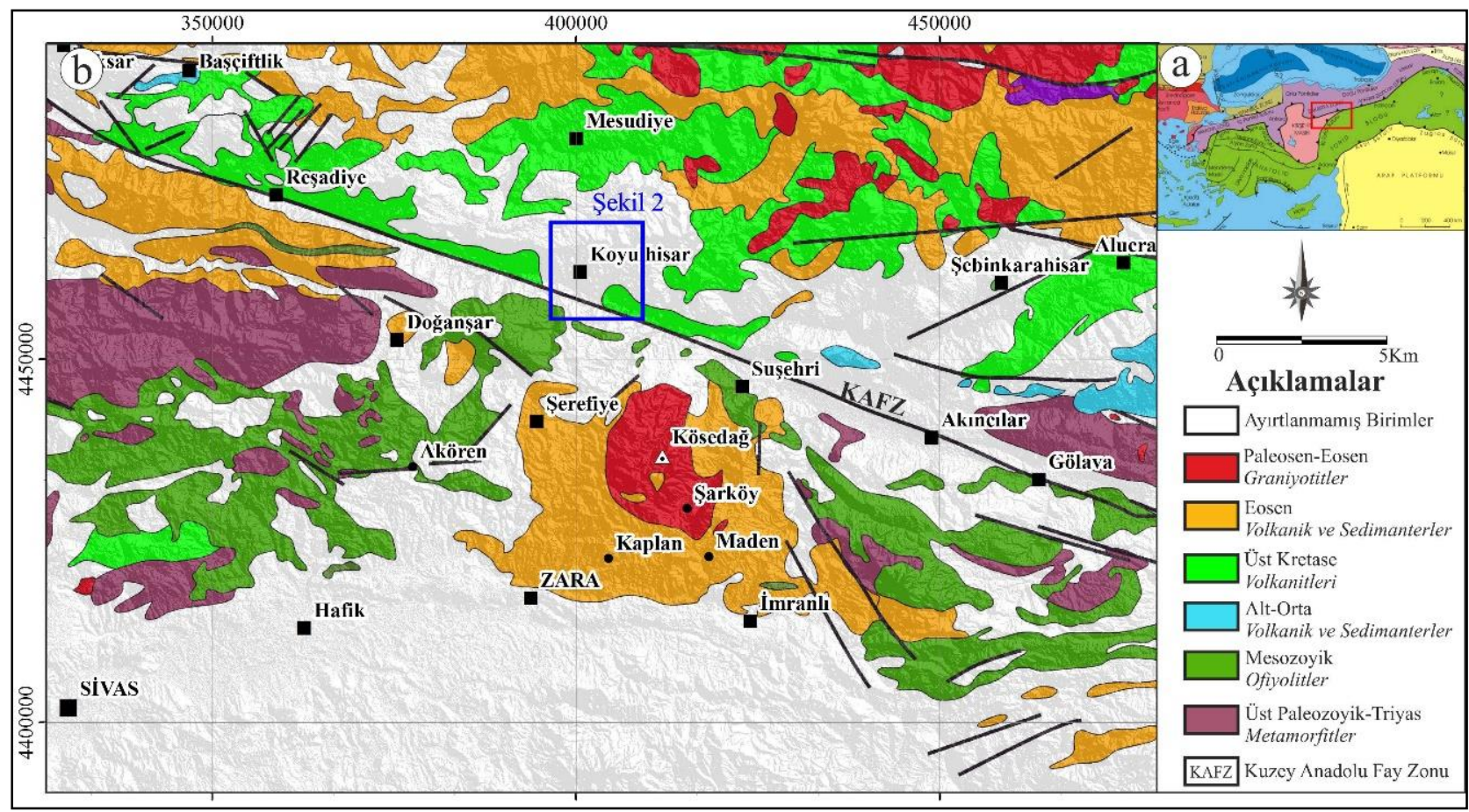

Şekil 1. a) Türkiye tektonik birimler haritası [30] b) İnceleme alanı çevresinin bölgesel jeoloji haritası ([29], [31]' den değiştirilmiştir).

İnceleme alanının yerel jeolojisini, Üst Kretase Refahiye Karmaşı̆̆ı, Orta-Üst Maestrihtiyen yaşlı Aşağıkale ve Üst Maestrihtiyen yaşlı İğdir, Orta-Üst Paleosen yaşlı Düdenyaylası, Pliyosen yaşlı Dumanlıca (Erdembaba) ve Pliyosen yaşlı Koyulhisar Formasyonları ile Kuvaterner yaşlı genç çökeller oluşturmaktadır (Şekil 2). [45], inceleme alanında yüzeyleyen Üst Kretase yaşlı kayaçların volkanik yay tipi bir ortamda çökeldiğini, Pliyosen-Kuvaterner dönemi çökellerin ise neotektonik dönemin ürünleri olduğunu öne sürmüştür.

Refahiye Karmaşı̆̆ı, genellikle birbiri ile tektonik ilişkili serpantinit, peridodit, gabro ve Tokat grubu metamorfitlerinden türemiş mermer, yeşilsist, ve metavolkanitlerinden oluşan bu kayaç topluluğunu Refahiye Karmaşığı olarak adlandırmışlardır. İnceleme alanının en yaşlı kaya birimi olan Refahiye Karmaşı̆̆ııın yaşının aynı araştırıcılar tarafından Üst Kretase-Paleosen yaşlı olduğu belirtilmiş olup bu çalışmada Üst Kretase yaşlı olarak kabul edilmiştir. Kayaç, genel olarak serpantinleşme göstermektedir [46].

Aşağıkale Formasyonu ilk olarak [45] tarafindan tanımlanmış olup Orta-Üst Maestrihtiyen (Üst Kretase) yaşındadır. Birimin taban seviyelerinde bazaltik lav akıntıları ile aglomera, orta seviyelerinde aglomera-tüf, üst seviyelerinde aglomera-kumtaşı ardalanması ile bazaltik lav akıntıları hakimdir.

İğdir formasyonu, ilk kez [47] tarafından adlandırılmış olup Üst Maestrihtiyen (Üst Kretase) yaşı verilmiştir. Birim, tabanda kırmızı renkli şeyl ve marn, orta seviyelerinde silt ve şeyl arakatkılı kumlu-fosilli kireçtaşları, istifin en üst seviyelerinde ise sarıml 1 beyaz renkli tabakalanmalı kumlu-fosilli kireçtaşlarından oluşmaktadır.

Düdenyaylası Formasyonu birimi, tabandan üste doğru, konglomera, siltli kireçtaşı, çamurtaşı, kumtaşı, biyomikritik kireçtaşı, siltli kireçtaşı, kumtaşı ile siltli marnlardan oluşmakta olup Orta-Üst Paleosen yaşlıdır [45].
İnceleme alanındaki en genç birim olan Koyulhisar Formasyonu, Pliyosen yaşlı olup Kuzey Anadolu Fay Zonu boyunca, taraça çakılları, talus, alüvyal yelpazeleri, flüvial ve alüvyon dolgulardan oluşan kum, silt ve çakıllardan oluşmaktadır [45], [48].

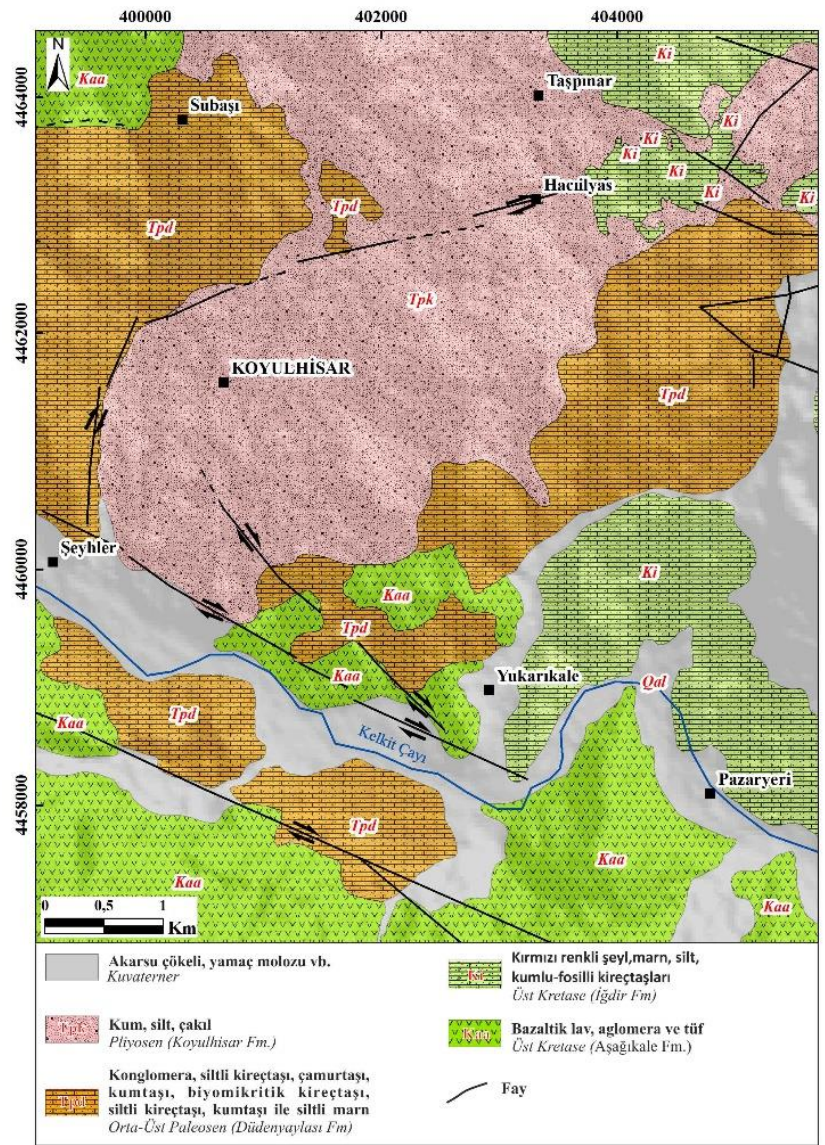

Şekil 2. Çalışma alanının yerel jeoloji haritası ([49]'dan değiştirilerek hazırlanmışıır). 


\section{Materyal ve Yöntemler}

\subsection{Sentinel-2A}

Sentinel-2A multispektral uydu görüntüsü (MSI) uydusu, 23 Haziran 2015'te ESA tarafından firlatılmış ve 10 günlük zamansal çözünürlüğe sahiptir. Sentinel-2A, 290 km'lik bir yörünge boyunca, 0.443 ila 2.190 mikrometre arasında Görünür ve Yakın Kızılötesi (VNIR ile Kısa Dalga Kızılötesi (SWIR) bölgelerinde 13 spektral banda sahip olup 20-60 metre metre mekânsal çözünürlüktedir (Tablo 1). Çalışmada, https://earthexplorer.usgs.gov adresinden ücretsiz olarak indirilen, 13 Eylül 2018 tarihli bulutsuz level 1C uydu görüntü verisi kullanılmıştır.

\subsection{Görüntü İşleme Yöntemleri}

Atmosferik saçılım nedeniyle görüntünün yansıtımında bozulmalar meydana gelir ve bu etkilerin giderilmesi gerekmektedir [50], [51]. Bu nedenle, Sentinel 2A uydu görüntüsüne ait VNIR ve SWIR spektral aralığındaki 13 spektral bantın QGIS 2.18 yazılımı ile atmosferik düzeltmeleri dos formatında yapılmış olup yüzey yansıtım değerleri 0 ile 1 yansıtma değer aralığına indirgenmiştir. Atmosferik düzeltme işleminden sonra, Sentinel-2A uydu görüntüsüne ait kullanılacak olan bantlar yeniden örnekleme yöntemi ile $10 \mathrm{~m}$ çözünürlüğe getirilmiştir. [52]'ye göre 1, 9 ve 10 nolu bantlar atmosferik düzeltmelerde kullanılmak üzere dizayn edildikleri için bu çalışmada gerçekleştirilecek olan litolojik özellik tespit çalışmasında kullanılmamışlardır. Geri kalan VNIR ve SWIR bantlar ise çalışma alanında karbonatlı mineral içeren sedimanter kayaç ile demiroksit/hidroksit ve hidroksil minerallerini içerebilecek özelliğe sahip volkanik kayaçların bir arada bulunması nedeniyle tercih edilmişlerdir. Görüntü işleme ve şekillerin son hali ENVI ve ARCGIS yazılımları kullanılarak gerçekleştirilmiştir.

Bant Oranlama yöntemi, basit matematiksel hesaplamalara dayalı bu yöntem hedef nesnenin anomalisini vurgulamak için kullanılmaktadır [53]. Bant oranlama yöntemi, litolojik birimleri, hidrotermal alterasyon ve değerli mineralleri tespit etmek için nesnelerin karakteristik soğurma ve yansıtma özelliklerinin spektral kontrastını göstermek için tasarlanmıştır [54], [55].

Minimum Gürültü Fraksiyonu (MNF) çok sayıda banttan oluşan bir görüntüde gürültüleri ayırmak ve sonraki işleme için hesaplama gereksinimlerini azaltmak için kullanılan etkili bir transformasyon aracıdır [56]. MNF tekniği iki aşamaya ayrılmıştır. Birinci aşamada veri gürültüleri ilişkilendirilemez ve yeniden ölçeklenir. İkinci aşamada temel bileşenler gürültüyle beyazlatılmış veriler türetilir. $\mathrm{Bu}$ durumda elde edilen verileri iki türe ayırmak mümkün olup birinci tip büyük özdeğer miktarı ve ikinci tip ise 1' e yakın özdeğerlerdir. [57]'e göre, büyük özdeğerli verilerin gürültüden ayrılması ve nihai sonuçların geliştirilmesinde avantajlıdır. Düşük özdeğerli veriler ise çok sınırlı bilgiye sahiptirler [58]. MNF özdeğerleri 1 'e yakın olan verilerinde çoğunlukla gürültü içermektedir [59]. $\mathrm{Bu}$ nedenle bu çalışmada KYM renk kombinasyonu oluşturmak için MNF özdeğer bileşenleri 1'den fazla olanlar dikkate alınmıştır.

Maksimum olasılık sınıflandırması (MLC) görüntü analisti tarafından önemli ön sınıflandırma girdisi gerektiren ve uydu verilerinin analizinde uzaktan algılamada en yaygın kullanılan denetimli sinıflandırma yöntemlerinden bir tanesidir [60]. Maksimum olasılık sinıflandırması, haritalanması istenilen özelliklerin "eğitim" örneklerinin seçilmesi dayanır [61]. Eğitim amaçlı örneklenen her bir veri bir spektral sınıfa sahiptir. Her bir spektral sınıfa ait eğitilmiş veri ise olasılık yoğunluk parametrelerini tahmin etmede kullanılır. Görüntüdeki her piksel için spektral sınıf olasılıkları için varyans/kovaryans matrisleri ile tanımlanan yoğunluk fonksiyonları kullanılır. Olasılığı en yüksek hesaplanan sınıf, sınıflandırılmış görüntü çıktısına atanır.

\section{Bulgular}

\subsection{Bant Oranlama}

Bu çalışmada, inceleme alanında bazaltik lav, aglomera ve tüf gibi volkanik kayaçlar ile kireçtaşı, kumtaşı, marn, şeyl ve konglomera gibi sedimanter kayaçlar kompleks bir şekilde yüzeylemektedir. Sentinel-2A uydu verisinin karbonat, mafik ve silikat minerallerinin haritalanmasında SWIR bölgede daha kısıtlı ve geniş bant aralığına sahip olması dezavantajdır. Ancak, VNIR bölgesinde ki çoklu banta sahip olması bu durumu avantaja çevirmektedir. $\mathrm{Bu}$ nedenle çalışma da, literatürde kabul görmüş Tablo 2' deki bant oranları tercih edilmiştir. Sentinel-2A uydu görüntüsüne ait en yüksek bilgi ve en düşük tekrarlanma içeren bantların korelasyon katsayıları ve standart sapmaları Tablo 3'te gösterilmektedir. İlk olarak, volkanik kayaçların yüzeylediği inceleme alanında, hidroksil içeren alterasyonların gelişebileceği ve sedimanter kayaçlardan ayırt edilebileceği düşünülerek önerilen 11/12 bant oranı uygulanmıştır (Şekil 3a). Sedimanter kayaçlar için ise, demirli silikat bant oranı (Şekil 3b), demir oksitli kayaçları ayırt etmek için ise bütün demirli oksitleri temsil eden bant oranı uygulanmıştır (Şekil 3c).

Tablo 1. Sentinel 2A uydu görüntülerinin özellikleri

\begin{tabular}{|l|c|c|}
\hline \multicolumn{3}{|c|}{ SENTINEL 2A } \\
\hline \multicolumn{1}{|c|}{ Bant No } & $\begin{array}{c}\text { Dalga Boyu } \\
\text { (mikrometre) }\end{array}$ & $\begin{array}{c}\text { Mekansal } \\
\text { Çözünürlük (m) }\end{array}$ \\
\hline $\begin{array}{l}\text { Bant 1-Coastal } \\
\text { aerosol }\end{array}$ & $0.433-0.453$ & 60 \\
\hline Bant 2-Blue & $0.458-0.522$ & 10 \\
\hline Bant 3-Green & $0.543-0.577$ & 10 \\
\hline Bant 4-Red & $0.650-0.680$ & 10 \\
\hline $\begin{array}{l}\text { Bant 5-Vegetation } \\
\text { Red Edge }\end{array}$ & $0.698-0.712$ & 20 \\
\hline $\begin{array}{l}\text { Bant 6-Vegetation } \\
\text { Red Edge }\end{array}$ & $0.733-0.747$ & 20 \\
\hline $\begin{array}{l}\text { Bant 7-Vegetation } \\
\text { Red Edge }\end{array}$ & $0.773-0.793$ & 20 \\
\hline Bant 8-NIR & $0.785-0.899$ & 10 \\
\hline $\begin{array}{l}\text { Bant 8A-Vegetation } \\
\text { Red Edge }\end{array}$ & $0.855-0.875$ & 20 \\
\hline Bant 9-Water vapour & $0.935-0.955$ & 60 \\
\hline Bant 10-SWIR-Cirrus & $1.365-1.385$ & 60 \\
\hline Bant 11-SWIR & $1.565-1.655$ & 20 \\
\hline Bant 12-SWIR & $2.100-2.280$ & 20 \\
\hline
\end{tabular}


Tablo 2. Landsat 8 OLI ve ASTER bant oranlarinın Sentinel-2A'ya karşıllk gelen bant oranları ([3], [62]).

\begin{tabular}{|l|c|c|c|}
\hline & ASTER & $\begin{array}{c}\text { Landsat-8 } \\
\text { OLI }\end{array}$ & $\begin{array}{c}\text { Sentinel-2A } \\
\text { MSI }\end{array}$ \\
\hline $\begin{array}{l}\text { Hidroksil } \\
\text { içeren } \\
\text { alterasyon }\end{array}$ & $4 /(5,6,7)$ & $5 / 7$ & $11 / 12$ \\
\hline $\begin{array}{l}\text { Bütün demir } \\
\text { oksitler }\end{array}$ & - & $4 / 2$ & $4 / 2$ \\
\hline $\begin{array}{l}\text { Demirli } \\
\text { silikatlar }\end{array}$ & $4 / 5$ & $6 / 7$ & $11 / 12$ \\
\hline
\end{tabular}

Ayrıca, kumtaşı, şeyl, bazaltik dayk, mika şist, meta-tüf ve farklı türde kireçtaşlarının ayrımı için ilk olarak [63] tarafından önerilen $(4+6) /(7+8),(2+11+6) /(3+4)$ ve $2 / 5$ bant oranlar1 kullanılmıştır (Şekil 3d).

Volkanik kayaçlar, yüzeysel ve hidrotermal çözeltilerin etkisiyle kolayca alterasyona uğrayabilirler. $\mathrm{Bu}$ nedenle, çalışmada kullanılan alterasyon bant oranının bu volkanik kayaçları sedimanter kayaçlardan ayırt edebileceği düşünülmüş ve uygulanmıştır. Ancak, elde edilen sonuçlarda, alterasyonun yoğun olarak sadece Tpk birimi içerisinde gözlenmesi ve genel olarak bir dağılım sergilemesi nedeniyle kayaçlar arasında bir farklılık göstermemiştir (Şekil 3a). Bu durum, inceleme alanında yüzeyleyen volkanik kayaçların (Kaa) ya çok fazla alterasyona uğramadığını ya da alterasyon üzerinden yapılacak bir ayırtlamada SWIR bölgesinde daha dar ve sık bantlara sahip multispectral (ASTER) yada hipekspektral uydu verileri tercih edilmesi gerektiğini göstermektedir. Şekil 3b'de demirli silikatlar için uygulanan bant oranında, renk rampasında kırmızı renkli alanlar inceleme alanında kumlu, siltli ve çakıllı yüzleklere karşılık gelmektedir. Bu kayaç türleri Tpk, Tpd ve $\mathrm{Ki}$ birimleri içerisinde ardalanmalı şekilde gözlendiği için birimlere ait sınırları kesin olarak ortaya çıkmamaktadır. Bu birimlerin dağılımı için belirlemek için arazi çalışması gerekmektedir.

Tablo 3. Sentinel-2 uydu görüntülerine ait bantların korelasyon matrisi ve her bir bandın standart sapmasl.

\begin{tabular}{|l|l|l|l|l|l|l|l|l|l|l|}
\hline Korelasyon & Bant 2 & Bant 3 & Bant 4 & Bant 5 & Bant 6 & Bant 7 & Bant 8 & Bant 11 & Bant 12 & Std. Sapma \\
\hline Bant 2 & 1,00 & & & & & & & & & 0,018 \\
\hline Bant 3 & 0,97 & 1,00 & & & & & & & & 0,025 \\
\hline Bant 4 & 0,95 & 0,97 & 1,00 & & & & & & & 0,039 \\
\hline Bant 5 & 0,87 & 0,93 & 0,94 & 1,00 & & & & & & 0,036 \\
\hline Bant 6 & 0,55 & 0,67 & 0,63 & 0,78 & 1,00 & & & & & 0,036 \\
\hline Bant 7 & 0,44 & 0,56 & 0,52 & 0,68 & 0,98 & 1,00 & & & & 0,041 \\
\hline Bant 8 & 0,40 & 0,53 & 0,48 & 0,61 & 0,93 & 0,95 & 1,00 & & & 0,042 \\
\hline Bant 11 & 0,65 & 0,71 & 0,77 & 0,85 & 0,73 & 0,68 & 0,65 & 1,00 & & 0,063 \\
\hline Bant 12 & 0,73 & 0,76 & 0,82 & 0,87 & 0,64 & 0,57 & 0,54 & 0,97 & 1,00 & 0,050 \\
\hline
\end{tabular}

Şekil 3c'de, kırmızı renkli alanlar, Ki formasyonuna ait kırmızı renkli şeyl seviyelerini ortaya çıkarmıştır. Bu birim aynı zamanda, jeolojik haritaya göre inceleme alanının kuzeybatısında Tpd formasyon sınırları içerisinde yoğun bir şekilde ortaya çıkmıştır. Bu nedenle, harita da Tpd formasyonu ile belirtilen alanin jeolojik sınırlarının yeniden gözden geçirilmesi ve çizilmesini gerektirmektedir. Son olarak, [63] tarafindan önerilen bant oranında ise bu kumlu, siltli, çakıllı seviyelerin mavimsi renklerde Tpk, Tpd ve Ki formasyonlarına ait sınırlar içerisinde dağılım göstermektedir (Şekil 3d). Kırmızı renkli şeyl seviyelerin ise açık yeşilimsi renklerde $\mathrm{Ki}$ ve Tpd formasyon sınırları içerisinde dağılım göstermektedir. Ayrıca, Kaa volkanik birimi ise Tpd formasyon sınırları içerisinde de yer yer ortaya çıkmaktadır. Bu bant oranlama sonuçlarına göre Ki ve Tpd formasyonları ile Kaa volkanik birimin sınırları yeniden çizilmesi gerektiğini göstermektedir.

\subsection{Minimum Gürültü Fraksiyonu}

Çalışmada, Sentinel-2A uydu verisinin 9 bandına MNF transformasyonu uygulanmış olup bileşenlere ait özdeğer ve yüzde değerleri Tablo 4'te gösterilmektedir. Şekil 4'te KYM bant kombinasyonu için sırasıyla MNF-1, MNF3 ve MNF-2 bileşenleri kullanılmıştır. Elde edilen kombinasyonda, Kırmızı renkli şeyl biriminin Ki ve Tpd formasyon sınırlarında dağılımı yeşil renkte gözlenmektedir. Ayrıca Tpk formasyonuna ait gevşek çökeller de morumsu renklerde diğer birimlerden ayırtlanmıştır. Kaa volkanik birimler ise bu görüntüde sarımsıkırmızımsı renklerde ayırtlanmıştır.

Tablo 4. Sentinel 2 A uydu görüntüsünün 9 bandına uygulanan minimum gürültü fraksiyon analiz sonuçlart.

\begin{tabular}{|l|c|c|}
\hline MNF & Özdeğer & \% \\
\hline Bant 1 & 37,20 & 47,67 \\
\hline Bant 2 & 12,79 & 16,39 \\
\hline Bant 3 & 11,36 & 14,56 \\
\hline Bant 4 & 7,42 & 9,51 \\
\hline Bant 5 & 3,19 & 4,09 \\
\hline Bant 6 & 1,92 & 2,46 \\
\hline Bant 7 & 1,51 & 1,94 \\
\hline Bant 8 & 1,35 & 1,73 \\
\hline Bant 9 & 1,29 & 1,66 \\
\hline
\end{tabular}



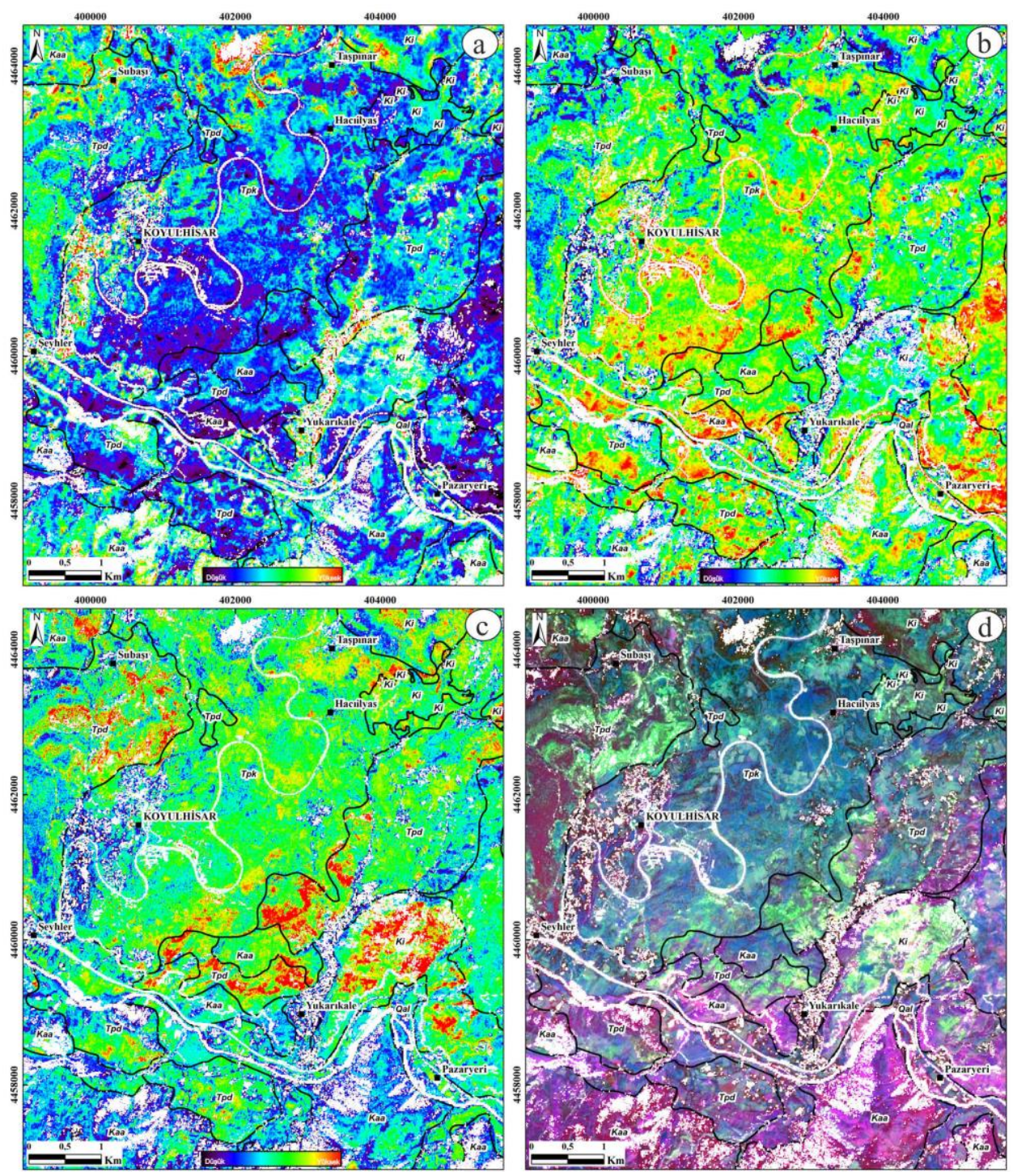

Şekil 3. Bant oranları. a) 11/12, b) 12/11, c) 4/2 ve d) $(4+6) /(7+8),(2+11+6) /(3+4)$, 2/5. (Siyah çizgiler jeolojik sinırları, beyaz alanlar ise bitki örtüsü, yol ve su kütlelerini göstermektedir).

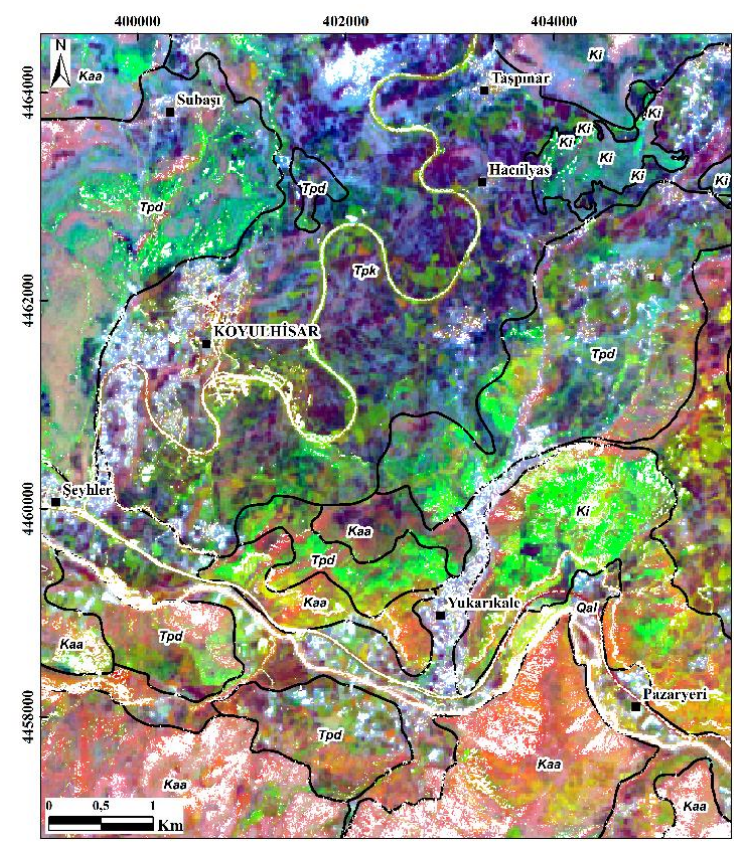

Sekil 4. MNF (K: MNF1, Y: MNF3 ve M: MNF2) (Siyah çizgiler jeolojik sinırları, beyaz alanlar ise bitki örtüsü, yol ve su kütlelerini göstermektedir).

\subsection{Maksimum Olabilirlik Sınıflandırması}

Denetimli sınıflandırmanın en önemli aşamalarından bir tanesi olan eğitilmiş verilerin doğru ve çalışma alanındaki litolojik özellikleri detaylı bir şekilde ortaya çıkaracak şekilde belirlenmesidir. $\mathrm{Bu}$ çalışmada, bazaltik lav, tüf, aglomera, kumtaşı, silttaşı, çakıltaşı, marn ve şeyl gibi birimlerin bir veya birden fazlasını içeren 5 farklı formasyonun dağılımlarını belirlemek için Sentinel 2-A uydu görüntüsümden farklı litolojileri temsilen endmember örnek yerleri belirlenmiştir (Şekil 6a). Endmember örnek yerleri, mevcut jeoloji haritasında ki jeolojik sınırlara göre belirlenmiştir. Maksimum olabilirlik yöntemi, her bir farklı litolojik özelliğe ait spektral sınıf verileri kullanılarak uydu görüntüne uygulanmıştır (Şekil 6b).

Sinıflandirmada elde edilen sonucun, bant oranlama ve MNF tekniklerinde olduğu gibi Ki formasyonuna ait kırmızı renkli şeyl birimine ait sınırları belirgin bir şekilde ortaya çıkarmıştır. Bunlara ek olarak, Kaa volkanik biriminin de çoğunlukla sedimanter kayalardan belirgin bir şekilde ayırtlanmıştır. Ancak, diğer sedimanter birimlerden, kum, silt, çamurtaşı, kireçtaşı gibi kayaçları temsil eden spektral verilerin sonuçları Tpd ve Tpk formasyonlarının birbiri içerisinde dağılım göstermektedir. Bunun nedeni benzer kaya birimlerinin 
aynı formasyonlarda da bulunmasından kaynaklandığı düşünülmektedir.

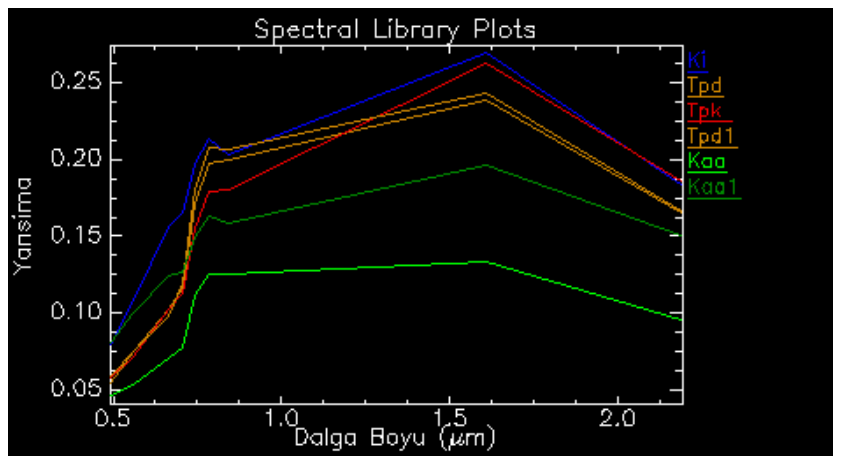

Şekil 5. Uydu görüntüsü üzerinden jeolojik birimlere ait spektral yansima grafikleri.

\section{Tartışma}

Çalışma kullanılan görüntü zenginleştirme teknikleri ve sınıflandırma yöntemleri sonuçları mevcut jeoloji haritası üzerinden değerlendirilmeye çalışılmıştır. Tpk, Tpd ve Ki formasyonları farklı jeolojik yaşlarda olsa da kumtaşı, silttaşı, çakıl gibi birbirine benzer sedimanter kayaçları barındırması nedeniyle görüntü zenginleştirme tekniklerinde bu birimler içerisinde dağılım gösterdiği için sınırları keskin bir şekilde belirlenememiştir. Fakat, jeolojik haritaya göre $\mathrm{Ki}$ formasyonuna ait olduğu bilinen kırmızı renkli şeyl birimi dikkate alınırsa; bu birim Google Earth görüntülerinde de belirgin bir şekilde gözlenebilmektedir. Yapılan bu incelemelerde de çalışma alanının batısında yüzlek veren bu birimler haritaya göre Tpd formasyon sınırları içerisine dahil edilmiştir. Arazinin sarp, engebeli ve bitki örtüsü nedeniyle ulaşılması zor alanlara sahip olması nedeniyle jeolojik haritalama sırasında arazi çalışmaları sırasında gözlenemediği için bu şekilde değerlendirildiği düşünülmektedir. Bu nedenle, jeolojik haritanın bu çalışmada elde edilen sonuçlara göre belirlenecek kontrol noktaları ile yeniden gözden geçirilip birimlere ait sınırların teyit edilmesi ve çizilmesi gerekebilir.

\section{Sonuçlar}

Bu çalışmada, Sentinel-2A uydu verisine bant oranlama, minimum gürültü fraksiyonu gibi görüntü zenginleştirme teknikleri ile maksimum olasılık gibi denetimli sınıflandırma yöntemi uygulanarak jeolojik birimlere ait sınırlar ortaya çıkarılmaya çalışılmıştır. Çalışmada, Bant oranlama ve MNF tekniklerinin inceleme alanında gözlenen sedimanter kayaç türlerine göre birimleri birbirinden ayırtlamada yararlı sonuçlar ortaya çıkarmıştır. Fakat, bu birimler farklı yaşlara göre formasyonlar şekinde gruplandırıldığı için formasyon sınırlarına yönelik kesin sonuçlar elde edilememiştir. Ancak, $\mathrm{Ki}$ formasyonuna ait kırmızı renkli şeyl biriminin sınırlarını belirgin bir şekilde ortaya çıkarmış ve inceleme alanının farklı bölgelerinde de olduğu tespit edilebilmiştir. Benzer şekilde aynı birime ait sınırlar maksimum olabilirlik sınıflandırması sonuçlarında da belirgin bir şekilde ortaya çıkmıştır. Bu sınıflandırma da ayrıca, volkanik ve sedimanter kayaçlar birbirinden ayırt edilebilmiştir.

Sonuç olarak, bitki örtüsünün yoğun olduğu ve benzer jeolojik birimleri içeren farklı formasyonların bir arada bulunduğu ve karbonat, silikat minerallerince zengin jeolojik birimlerin yüzeylediği bölgelerde Sentinel-2A uydu verisinin yetersiz kaldığını göstermektedir. Ancak, diğer birimlerden kimyasal ve/veya fiziksel olarak farklı özelliklere sahip jeolojik birimlerin sınırlarının tespitinde oldukça yararlı bilgiler sunabileceğini göstermiştir. Özellikle Sentinel-2A uydu verisinin VNIR bölgede fazla sayıda bant içermesi nedeniyle demir oksit içeriği yüksek jeolojik birimlerin ayırt edilebilmesinde oldukça yararlı olabileceği söylenebilir.
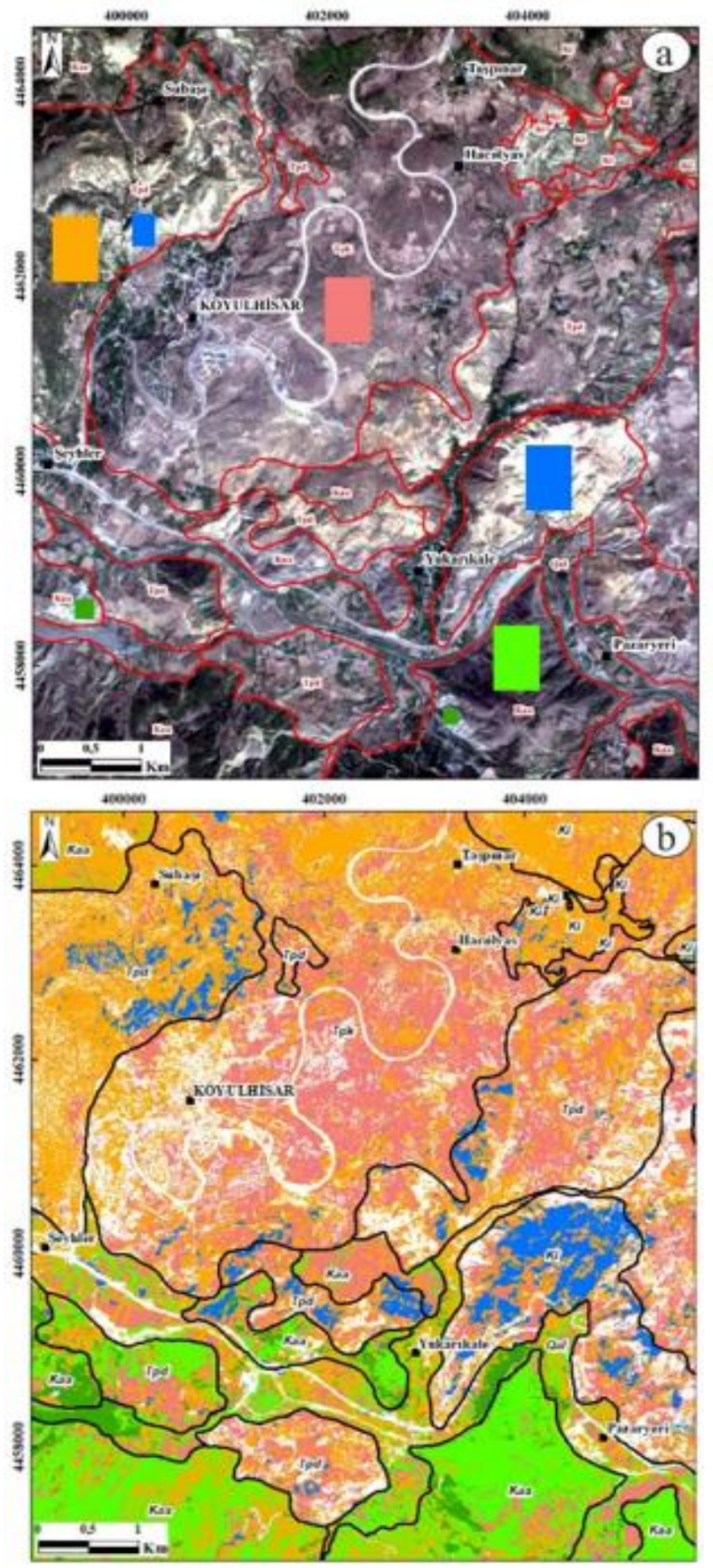

Şekil 6. a) Litolojilere göre elde edilen endmemberların uydu görüntüsü üzerinde dağılımı, b) maksimum olasılık sonucu (Jeolojik birimler Şekil 2'deki gibi)

\section{Teşekkür}

$\mathrm{Bu}$ araştırma Sivas Cumhuriyet Üniversitesi Bilimsel Araştırma ve Projeler birimi tarafından M-722 nolu proje olarak desteklenmiştir. 


\section{Kaynakça}

[1] F. A. Kruse, J. W. Boardman, and J. F. Huntington, 'Comparison of airborne hyperspectral data and EO-1 Hyperion for mineral mapping', IEEE Trans. Geosci. Remote Sens., 2003.

[2] W. Ge, Q. Cheng, Y. Tang, L. Jing, and C. Gao, 'Lithological classification using Sentinel-2A data in the Shibanjing ophiolite complex in Inner Mongolia, China', Remote Sens., 2018.

[3] F. D. Van der Meer, H. M. A. van der Werff, and F. J. A. van Ruitenbeek, 'Potential of ESA's Sentinel-2 for geological applications', Remote Sens. Environ., 2014.

[4] H. van der Werff and F. van der Meer, 'Sentinel-2 for mapping iron absorption feature parameters', Remote Sens., 2015.

[5] Z. Malenovský et al., 'Sentinels for science: Potential of Sentinel-1, -2, and -3 missions for scientific observations of ocean, cryosphere, and land', Remote Sens. Environ., 2012.

[6] K. Richter, C. Atzberger, F. Vuolo, P. Weihs, and G. D'urso, 'Experimental assessment of the Sentinel-2 band setting for RTM-based LAI retrieval of sugar beet and maize', Can. J. Remote Sens., 2009.

[7] C. Atzberger and K. Richter, 'Spatially constrained inversion of radiative transfer models for improved LAI mapping from future Sentinel-2 imagery', Remote Sens. Environ., 2012.

[8] J. G. P. W. Clevers and A. A. Gitelson, 'Remote estimation of crop and grass chlorophyll and nitrogen content using red-edge bands on sentinel-2 and-3', Int . J. Appl. Earth Obs. Geoinf., 2013.

[9] K. Toming, T. Kutser, A. Laas, M. Sepp, B. Paavel, and T. Nõges, 'First experiences in mapping lakewater quality parameters with sentinel-2 MSI imagery', Remote Sens., 2016.

[10] D. Stratoulias, H. Balzter, O. Sykioti, A. Zlinszky, and V. R. Tóth, 'Evaluating sentinel-2 for lakeshore habitat mapping based on airborne hyperspectral data', Sensors (Switzerland), 2015.

[11] M. Immitzer, F. Vuolo, and C. Atzberger, 'First experience with Sentinel-2 data for crop and tree species classifications in central Europe', Remote Sens., 2016.

[12] M. S. Salama, M. Radwan, and R. van der Velde, 'A hydro-optical model for deriving water quality variables from satellite images (HydroSat): A case study of the Nile River demonstrating the future Sentinel-2 capabilities', Phys. Chem. Earth, 2012.

[13] J. Hedley, C. Roelfsema, B. Koetz, and S. Phinn, 'Capability of the Sentinel 2 mission for tropical coral reef mapping and coral bleaching detection', Remote Sens. Environ., 2012.

[14] H. van der Werff and F. van der Meer, 'Sentinel-2A MSI and Landsat 8 OLI provide data continuity for geological remote sensing', Remote Sens., 2016.

[15] A. El Atillah, Z. E. A. El Morjani, and M. Souhassou, 'Use of the Sentinel-2A Multispectral Image for LithoStructural and Alteration Mapping in Al Glo'a Map Sheet $(1 / 50,000)$ (Bou Azzer-El Graara Inlier, Central Anti-Atlas, Morocco)', Artif. Satell., 2019.

[16] B. Hu, Y. Xu, B. Wan, X. Wu, and G. Yi, 'Hydrothermally altered mineral mapping using synthetic application of Sentinel-2A MSI, ASTER and Hyperion data in the Duolong area, Tibetan Plateau, China', Ore Geol. Rev., 2018.

[17] J. Lin, R. Wang, B. Zhao, and S. Cheng, 'A comprehensive scheme for lithological mapping using Sentinel-2A and ASTER GDEM in weathered and vegetated coastal zone, Southern China', Open Geosci., 2019.

[18] M. Karaman, 'Grafit Cevherleşmelerinin Sentinel-2 Uydu Görüntülerinden Belirlenmesinde En Uygun Bant Kombinasyonları', Avrupa Bilim ve Teknol. Derg., vol. 25, pp. 749-757, 2021.

[19] H. A. Baran, 'Hakkâri ili baz metal yataklarının uzaktan algılama ile belirlenmesi', Gümüşhane Fen Bilim. Enstitüsü Derg., vol. 11, no. 2, pp. 339-347, 2021.

[20] C. Zabc1, 'Çok bantlı Landsat 8-OLI ve Sentinel-2A MSI uydu görüntülerinin karşılaştırmalı jeoloji uygulaması: Örnek çalışma alanı olarak Doğu Anadolu Fayı boyunca Palu - Hazar Gölü bölgesi (Elazı̆̆, Türkiye)', Geomatik, vol. 6, no. 3, pp. 238-246, 2021.

[21] R. Ulusay, Ö. Aydan, and R. Kilic, 'Geotechnical assessment of the 2005 Kuzulu landslide (Turkey)', Eng. Geol., 2007.

[22] I. Yilmaz, 'A case study from Koyulhisar (SivasTurkey) for landslide susceptibility mapping by artificial neural networks', Bull. Eng. Geol. Environ., 2009.

[23] I. Yilmaz, 'Comparison of landslide susceptibility mapping methodologies for Koyulhisar, Turkey: Conditional probability, logistic regression, artificial neural networks, and support vector machine', Environ. Earth Sci., 2010.

[24] A. Yıldırım, 'Koyulhisar-Kuzulu (Sivas) Heyelanının Jeomorfolojik Etüdü’, Doğu Coğrafya Derg., vol. 11, no. 15 , pp. 323-338, 2011.

[25] M. E. Cihangir, T. Görüm, and H. A. Nefeslioğlu, 'Heyelan tetikleyici faktörlerine bağlı mekânsal hassasiyet değerlendirmesi', Türk Cograf. Derg., vol. 70, pp. 133-142, 2018.

[26] A. Polat and D. Erik, 'Debris flow susceptibility and propagation assessment in West Koyulhisar, Turkey', $J$. Mt. Sci., 2020.

[27] Ö. Gürsoy and Ş. Kaya, 'Detecting of Lithological Units by Using Terrestrial Spectral Data and Remote Sensing Image', J. Indian Soc. Remote Sens., vol. 45, no. 2, 2017.

[28] Ö. Gürsoy, Ş. Kaya, Z. Çakir, O. Tatar, and O. Canbaz, 'Determining lateral offsets of rocks along the eastern part of the North Anatolian Fault Zone (Turkey) using spectral classification of satellite images and field measurements', Geomatics, Nat. Hazards Risk, vol. 8, no. 2, pp. 1276-1288, 2017.

[29] O. Canbaz, Ö. Gürsoy, and A. Gökce, 'Detecting Clay Minerals in Hydrothermal Alteration Areas with Integration of ASTER Image and Spectral Data in Kösedag-Zara (Sivas), Turkey', J. Geol. Soc. India, vol. 91, no. 4, pp. 389-516, 2018.

[30] A. I. Okay and O. Tüysüz, 'Tethyan sutures of northern Turkey', Geol. Soc. London, Spec. Publ., vol. 156, no. 1, pp. 475-515, 1999.

[31] MTA, '1/500.000 Türkiye Jeoloji Haritas1, Sivas Paftası. Maden Tetkik ve Arama Genel Müdürlüğü’, Ankara., 2002. 
[32] İ. Ketin, 'On the tectonic-mechanical consequences of the great Anatolian earthquakes of the last decenions', Geol Rundsch, vol. 36, pp. 77-83, 1948.

[33] İ. Seymen, 'Tectonic feature of North Anatolian Fault zone in Kelkit valley section', Istanbul Tech. Univ., 1975.

[34] M. E. Ayhan et al., 'Kinematics of the $\mathrm{Mw}=7.2,12$ November 1999, Düzce, Turkey Earthquake', Geophys. Res. Lett., 2001.

[35] C. Zabci, T. Sançar, H. S. Akyuz, and N. G. Kiyak, 'Spatial slip behavior of large strike-slip fault belts: Implications for the Holocene slip rates of the eastern termination of the North Anatolian Fault, Turkey', $J$. Geophys. Res. Solid Earth, 2015.

[36] O. Tatar et al., 'Crustal deformation and kinematics of the Eastern Part of the North Anatolian Fault Zone (Turkey) from GPS measurements', Tectonophysics, 2012.

[37] Y. Tatar, 'Tectonic structures along the North Anatolian fault zone, northeast of Refahiye (Erzincan)', Tectonophysics, 1975.

[38] Y. Tatar, 'Tectonic investigations on the ErzincanRefahiye section of the North Anatolian Fault Zone', Hacettepe Univ. Earthscience, vol. 1, no. 2, pp. 201236, 1978.

[39] A. M. C. Şengör, 'The North Anatolian transform fault: Its age, offset and tectonic significance', J. Geol. Soc. London., 1979.

[40] S. Sipahioğlu, . 'Investigation of earthquake activity of North Anatolian Fault Zone and its surroundings', Bull. Earthq. Res. Ankara, vol. 45, pp. 5-138, 1984.

[41] A. M. C. Sengor, N. Gorur, and F. Saroglu, 'Strike-slip faulting and related basin formation in zones of tectonic escape: Turkey as a case study.', Strike-slip Deform. basin Form. Sediment., 1985.

[42] F. Şaroğlu, 'Age and offset of the North Anatolian fault', METU J Pure Appl Sci, vol. 21, no. 1-3, pp. 6579,1988

[43] O. Tatar, 'Determination of extension direction in naturally deformed limestones within strike-slip fault zones using microcracks; Niksar Basin (Turkey) as case study', 2Turkish J. Earth Sci., vol. 5, pp. 45-33, 1996.

[44] C. Yaltirak, B. Alpar, and H. Yüce, 'Tectonic elements controlling the evolution of the Gulf of Saros (northeastern Aegean Sea, Turkey)', Tectonophysics, 1998.

[45] V. Toprak, 'Neotectonic characteristics of the North Anatolian Fault Zone between Koyulhisar and Suşehri', METU J. Pure Ap. Sci. 21:155-66, 1988.

[46] A. Yılmaz, 'Yukarı Kelkit Çayı ile Munzur Dağları Arasının Temel Jeoloji Özellikleri ve Yapısal Evrimi', Türkiye Jeol. Bülteni, vol. 28, no. August, pp. 79-92, 1985.

[47] İ. Terlemez and A. Yılmaz, 'Ünye-OrduReşadiyeKoyulhisar-Karaçayır-Hafik arasında kalan bölgesinin jeolojisi. Rapor No: 6671. Maden Tetkik ve Arama Genel Müdürlügü, Ankara', 1980.

[48] Ş. Uysal, Y. Bedi, İ. Kurt, and F. Kılınç, 'Koyulhisar (Sivas) Dolayının Jeolojisi. MTA Rapor No: 9838, Maden Tetkik ve Arama Genel Müdürlügü, Ankara (Yayınlanmamış)', 1995.

[49] M. Demirel, O. Tatar, and F. Koçbulut, 'Kuzey Anadolu Fay Zonu Üzerinde Koyulhisar (Sivas) ve Yakın
Çevresindeki Fayların Kinematik Özellikleri', Türkiye Jeol. Bülteni, vol. 59, no. 8, pp. 357-370, 2016.

[50] E. P. Green, P. J. Mumbay, A. J. Edwards, and C. Clarck, 'Remote Sensing Handbook for Tropical Coastal Management.', Coast. Manag. Sourcebooks 3, Unesco, Paris, 2000.

[51] M. S. Thalib, N. Nurdin, and A. Aris, 'The Ability of Lyzenga's Algorithm for Seagrass Mapping using Sentinel-2A Imagery on Small Island, Spermonde Archipelago, Indonesia', in IOP Conference Series: Earth and Environmental Science, 2018.

[52] M. Drusch et al., 'Sentinel-2: ESA's Optical HighResolution Mission for GMES Operational Services', Remote Sens. Environ., 2012.

[53] M. J. Abrams, D. Brown, L. Lepley, and R. Sadowski, 'Remote sensing for porphyry copper deposits in southern Arizona.', Econ. Geol., vol. 78, no. 4, pp. 591604, 1983.

[54] K. Okada and M. Ishii, 'ASTER spectral ratioing for lithological mapping in the Arabian-Nubian shield, the Neoproterozoic Wadi Kid area, Sinai, Egypt', in International Geosciences and Remote Sensing Symposium "Better Understanding of Earth Environment”, 1993, p. Vol. 93, 126-128.

[55] S. Gad and T. Kusky, 'ASTER spectral ratioing for lithological mapping in the Arabian-Nubian shield, the Neoproterozoic Wadi Kid area, Sinai, Egypt', Gondwana Res., vol. 11, no. 3, pp. 326-335, 2007.

[56] A. A. Green, M. Berman, P. Switzer, and M. D. Craig, 'A Transformation for Ordering Multispectral Data in Terms of Image Quality with Implications for Noise Removal', IEEE Trans. Geosci. Remote Sens., 1988.

[57] R. O. Green, B. E. Pavri, and T. G. Chrien, 'On-orbit radiometric and spectral calibration characteristics of EO-1 hyperion derived with an underflight of AVIRIS and In situ measurements at Salar de Arizaro, Argentina', IEEE Trans. Geosci. Remote Sens., 2003.

[58] J. W. Boardman and R. O. Green, 'Exploring the spectral variability of the earth as measured by AVIRIS in 1999. Summaries of the ninth annual JPL airborne geosciences workshop. Jet Propulsion Laboratory Special Publication 18', 2000, p. 10.

[59] jensen, 'Introductory Digital Image Processing (3rd edition). Prentice Hall.', Int. J. Remote Sens., 2005.

[60] T. M. Lillesand and R. W. Kiefer, 'Remote sensing and image interpretation.', Remote Sens. image Interpret., 1979.

[61] T. Salehi and M. H. Tangestani, 'Evaluation of WorldView-3 VNIR and SWIR Data for Hydrothermal Alteration Mapping for Mineral Exploration: Case Study from Northeastern Isfahan, Iran', Nat. Resour. Res., 2020.

[62] F. F. Sabins, 'Remote sensing for mineral exploration', Ore Geol. Rev., 1999.

[63] M. H. Tangestani and S. Shayeganpour, 'Mapping a lithologically complex terrain using Sentinel-2A data: a case study of Suriyan area, southwestern Iran', Int. J. Remote Sens., 2020. 